\title{
Serum immunoreactive trypsin concentrations in diabetic children
}

\author{
ANNE MOFFAT, ${ }^{*}$ VINCENT MARKS, ${ }^{*}$ AND DR GAMBLE $\dagger$ \\ From the *Department of Clinical Biochemistry, St Luke's Hospital, Warren Road, Guildford, Surrey \\ GUI 3NT, and the †Public Health Laboratory, West Park Hospital, Epsom, Surrey KT19 8PB, UK
}

SUMMARY Serum immunoreactive trypsin (SIT) concentrations measured in 616 children with diabetes of recent onset were low, in both boys and girls, in comparison with reference ranges established in patients with non-diabetic, non-infectious illnesses. The mean SIT concentration was $60 \%$ of the mean reference level in children tested within three weeks of the onset of diabetes, and about $40 \%$ in patients tested six months after the onset of diabetes. Very low SIT levels were found in about $10 \%$ of patients, most of whom had no measurable SIT by the assay procedure employed. These very low SIT concentrations were more frequent in older children aged 6-15 years, and in children tested at about 5-6 months after onset. Repeat tests on some of the children showed that the very low SIT levels were generally present for only a limited period.

It has long been suspected that insulin-dependent diabetes may sometimes follow acute pancreatitis, ${ }^{1}$ but in most cases there is no history of antecedent illness to suggest prior pancreatic disease. However, exocrine pancreatic dysfunction has been reported in a proportion of insulin-dependent diabetics, which increased with the duration of diabetes. ${ }^{2}$ Whether this dysfunction occurs before the onset of diabetes or is a result of it, and the mechanism underlying the exocrine abnormalities, are at present unknown.

The difficulties of conventional tests of pancreatic functions have precluded large-scale investigations in diabetics, but the recent development of a radioimmunoassay for serum immunoreactive trypsin (SIT), which is not affected by the presence of naturally occurring trypsin inhibitors, ${ }^{3}$ makes such investigations feasible.

Dandona and colleagues ${ }^{4}$ reported low levels of SIT in 22 of 40 patients aged 14-65 years with diabetes under treatment with insulin or sulphonylureas. In the present study we have extended these observations by examining SIT concentrations in diabetic children in relation to age, sex, and duration of symptoms.

\section{Material and methods}

Patients studied included 616 children with insulindependent diabetes aged 0-15, of whom $333(54 \%)$

Received for publication 14 January 1980 were boys. The duration of diabetic symptoms ranged from a few days to two years. Sixty-six patients with diabetes of from two to 16 years' duration were also tested, but these were almost all aged 16 or more years.

Serum specimens from these patients were surplus from samples submitted for other investigations. All were submitted by post at ambient temperature, as unfrozen whole blood or serum, and bacterial contamination was occasionally present. Sera were stored at $-20^{\circ} \mathrm{C}$ on receipt in the laboratory but had been thawed and refrozen a number of times for other tests before the SIT assay.

Age-specific reference ranges of SIT concentration were established in non-diabetic patients in a previous investigation ${ }^{5}$ using surplus serum specimens handled and stored in a similar way to the samples from the diabetic subjects. The reference data were derived from 55 children and 52 adults, in whom geometric mean SIT concentrations were 167 (range 79-340) $\mu \mathrm{g} / 1$ for children and 213 (range 98-460) $\mu \mathrm{g} / \mathrm{l}$ for adults. Since logarithmic values of SIT fit the normal distribution pattern better than arithmetic values, ${ }^{5}$ in this study we have analysed and compared log rather than arithmetic SIT concentrations in the different patient groups.

SIT concentrations were measured by radioimmunoassay using a double antibody technique. ${ }^{3}$ Highly purified human trypsin was used as immunogen and for radioiodination. Antibodies were produced in rabbits. Radioiodination was per- 
formed by the chloramine-T method using ${ }^{125}$ I labelled sodium iodide. Standards used in the assay were made from a semipurified preparation of human trypsin, and they ranged from 80 to $1280 \mu \mathrm{g} / \mathrm{l}$. Kits for the assays were supplied by Behring Institute, Hoechst UK Ltd. All samples were assayed in duplicate. The sensitivity of the assay was $34 \mu \mathrm{g} / \mathrm{l}$ with $90 \%$ confidence limits or $24 \mu \mathrm{g} / \mathrm{l}$ with $18 \%$ confidence limits. Within-assay coefficient of variation was $14 \%$ for a low concentration control serum and $15 \%$ for a high concentration control serum.

\section{Results}

SIT concentrations were clearly reduced in diabetic children (Fig. 1); 39\% (205/616) were below the reference range, and there was no significant difference between results for boys or girls. The results showed a bimodal distribution with the majority distributed approximately normally about a mode of $100 \mu \mathrm{g} / \mathrm{l}$, and a smaller group of 45 patients with no measurable SIT by the assay procedure used.

Mean SIT concentrations decreased significantly with the duration of diabetes (Fig. 2), and this decline was due to two factors. Firstly, the proportion of patients with no measurable SIT increased with the duration of diabetes to $14.6 \%(6 / 41)$ at 20-30 weeks, declining thereafter. Secondly, in patients with measurable levels of SIT, the mean concentration declined gradually in the six months after onset. There was an apparent increase in SIT levels in patients tested more than two years after the onset of diabetes (Fig. 2), but these patients were mainly adults, and their mean SIT concentration as a proportion of the mean reference concentration for adults $(35.1 \%)$ was similar to that for children tested between 30 and 99 weeks after onset when expressed as a proportion of the mean reference concentration for children $(35.7 \%)$. There was therefore no evidence of a significant change in mean SIT concentrations after the first six months of diabetes other than the normal increase with age.

Mean SIT concentrations varied with age at onset of diabetes (Fig. 3). The mean concentrations of SIT in samples with measurable levels showed little variation with age, but the proportion of patients without measurable SIT was greater in patients who were older at the onset of diabetes.

The decline in the proportion of patients without measurable SIT, after a peak incidence between 20 and 30 weeks after onset of diabetes, suggested that SIT may sometimes fall to very low levels during the early stages of the disease but subsequently recovers.

In order to investigate this possibility further, a number of patients who had been tested within the first year of their diabetes were retested after an interval of about one year. Of 36 patients who were initially 'positive', two had no measurable SIT in the later specimen, but the remainder showed little

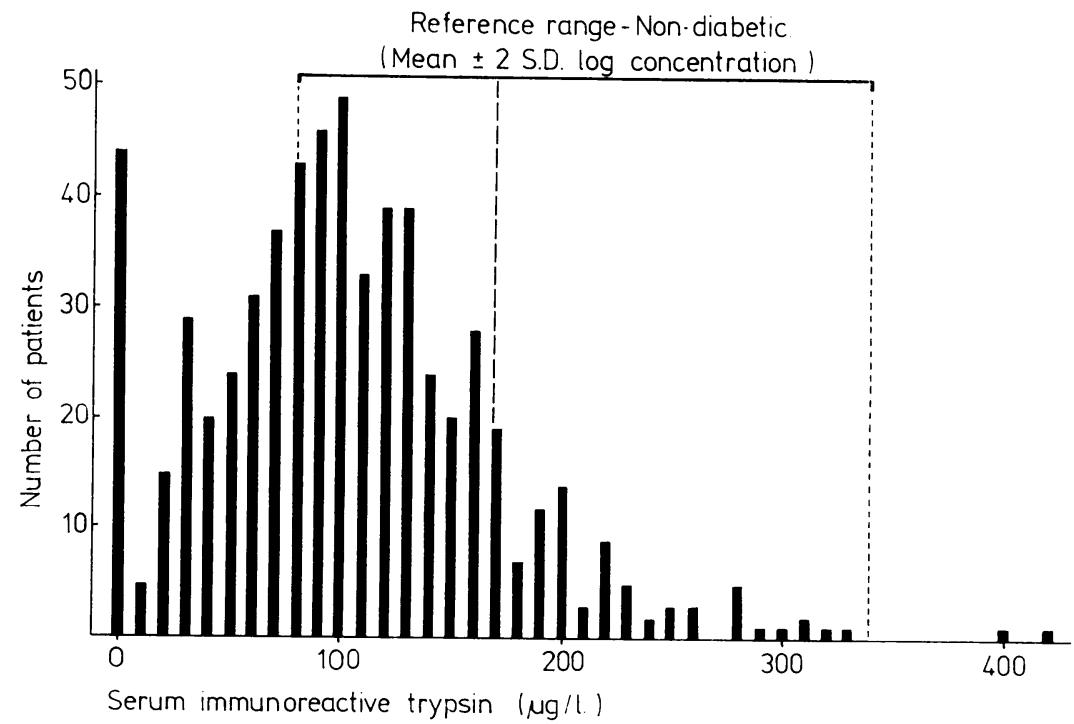

Fig. 1 Distribution of serum immunoreactive trypsin concentrations in 616 diabetic children. Interrupted lines show reference range for children (geometric mean concentrations $\pm 2 S D$ ). 


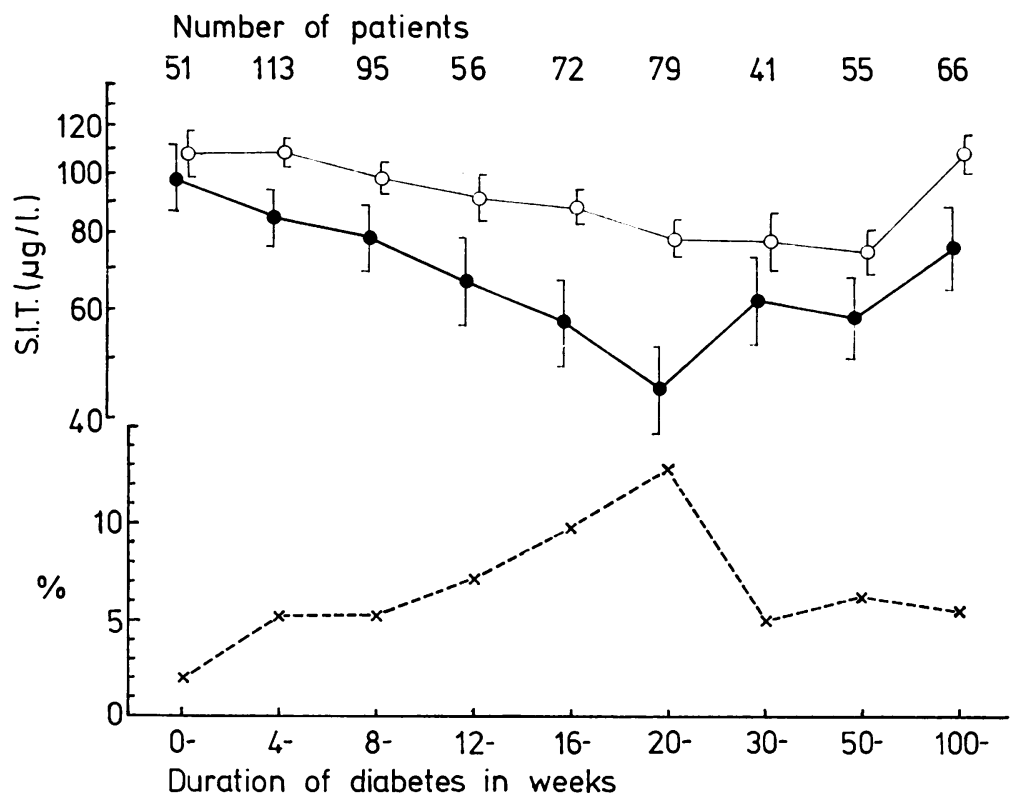

Fig. 2 Serum immunoreactive trypsin (SIT) concentrations ( \pm SEM) by duration of diabetic symptoms in all patients (solid circles) and 'positive' patients only (open circles). Dotted line shows proportions of patients with no measurable SIT.
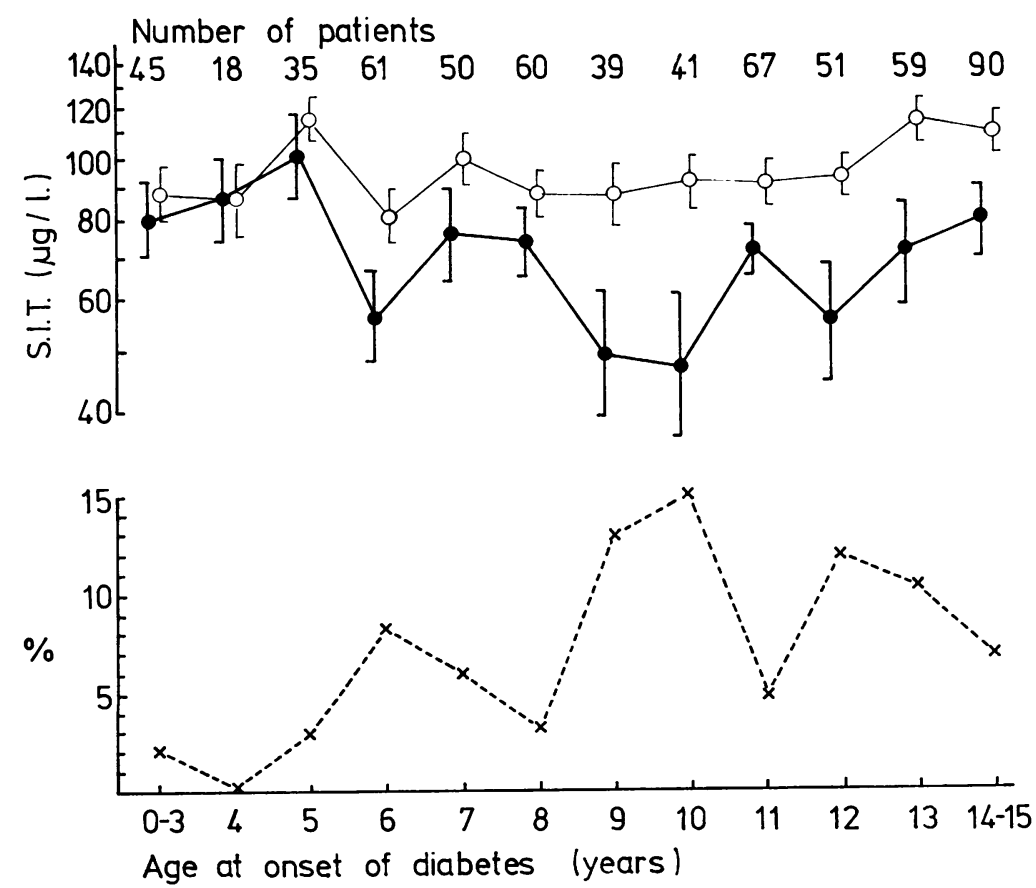

Fig. 3 Serum immunoreactive trypsin (SIT) concentrations ( \pm SEM) by age at onset of diabetes in all patients (solid circles) and 'positive' patients only (open circles). Dotted line shows proportions of patients with no measurable SIT. 
change. On the other hand, of 13 patients with no measurable SIT in the first sample, only one was still 'negative' in the retest, one had a low concentration $(10 \mu \mathrm{g} / \mathrm{l})$, and in the remainder levels ranged from 60 to $140 \mu \mathrm{g} / \mathrm{l}$ (mean $99 \mu \mathrm{g} / \mathrm{l}$ ). It was evident, therefore, that absence of measurable SIT was generally a transient phenomenon.

\section{Discussion}

The possibility that unsatisfactory conditions of transport and storage of serum samples had affected the results was considered unlikely since diabetic and reference sera had been treated similarly; moreover, variations in SIT levels were too systematic to be explained in this way.

The precision of the SIT assay was poor for samples containing less than $24 \mu \mathrm{g} / \mathrm{l}$, but replicates were generally consistent, and consequently the results obtained are presented. Although the accuracy of these low results is doubtful, they clearly reflect the very low levels of SIT present, and a more precise result would not have affected the conclusions we have drawn from them.

Dandona et al. ${ }^{4}$ reported subnormal SIT concentrations in insulin and sulphonylurea treated diabetics aged 14-65 years. Our results extend these observations in respect of insulin treated diabetics aged 0-15 years at onset. We found that the mean SIT concentration was already reduced by $40 \%$ at the onset of symptoms and continued to decline during the first six months after diagnosis. This is due to both an increase in the number of patients who exhibited a transient absence of measurable SIT and to a gradual decline in the mean SIT concentration in the rest.

Trypsin is thought to enter the plasma by reabsorption from the gut, ${ }^{6}$ and the low SIT levels observed in diabetics could therefore be due to malabsorption, but, so far as we know, malabsorption is not a feature of early diabetes. A more probable explanation of the low SIT levels is a reduction in the synthesis and/or secretion of trypsin and trypsinogen by the exocrine pancreas. The transience of the very low levels in some of the patients suggests that this may be due to a functional disturbance rather than to anatomical loss of exocrine tissue.

Since reduced SIT concentrations were found at the onset of diabetes, the changes in exocrine function they represent might well have occurred before the onset of clinical symptoms and were clearly unrelated to treatment. Diabetes occasionally follows an acute attack of pancreatitis, and in mumps and Coxsackie B virus infections, both of which may cause diabetes, there may be silent involvement of the pancreas. ${ }^{5}$ There is, however, no evidence that severe infective damage of the exocrine pancreas is commonly present at onset of diabetes in patients in the developed countries; indeed, the presence of SIT concentrations above the reference range in only two of the 616 children in the present study suggests that pancreatitis at the time of onset of diabetes is rare.

It has been suggested that the reduction in pancreatic exocrine function observed in some diabetic subjects might result from the loss of a trophic effect normally exerted by the $B$ cells on the nearby acinar cells through the agency of insulin. ${ }^{78}$ An attempt to test this hypothesis showed a good correlation in diabetics between residual $B$ cell function, as reflected by C-peptide immunoreactivity, and the capacity to secrete amylase but not trypsin. ${ }^{9}$ A diminished trophic effect of insulin on the acinar cells could nonetheless still be important as a component of changes in a more complex, multihormonal, control mechanism, in which the individual contributions may be difficult to demonstrate. Each of the three other major pancreatic hormones, namely, glucagon, ${ }^{10}$ somatostatin, ${ }^{11} 12$ and pancreatic polypeptide, ${ }^{13}$ is able to suppress exocrine pancreatic secretion, and while $B$ cells are lost in insulin-dependent diabetes, there is evidence that $\mathbf{A}$ and $\mathbf{D}$ cells normally survive and that pancreatic polypeptide cells may even proliferate. ${ }^{14}$ Thus alterations in pancreatic exocrine function in diabetes may reflect changes in the secretion of several islet hormones-not just insulin, the nett effect being suppression of trypsin secretion.

Firm conclusions about the mechanism of changes in SIT concentration in diabetes must, however, await the results of direct studies of exocrine pancreatic function, which were not undertaken in the present study.

We gratefully acknowledge the support of the British Diabetic Association and the many physicians who have notified their patients to the Association and supplied serum samples. Thanks are also due to $\mathrm{Dr}$ M Redshaw, of Behring Institute, Hoechst, UK, for the RIA-ghost Trypsin Radioimmunoassay kits.

\section{References}

${ }^{1}$ Stang J. (1864). Cited by Gunderson E. J Infect Dis 1927; 41:197-202.

${ }^{2}$ Frier BM, Saunders JHB, Wormsley KT, Bouchier AD. Exocrine pancreatic function in juvenile-onset diabetes mellitus. Gut 1976;17:685-91.

${ }^{3}$ Elias E, Redshaw M, Wood T. Diagnostic importance of changes in circulating concentrations of immunoreactive trypsin. Lancet 1977;2:66-8.

${ }^{4}$ Dandona P, Elias E, Beckett AG. Serum trypsin concentrations in diabetes mellitus. Brit Med J 1978;3: 1126-7.

${ }^{5}$ Gamble DR, Moffat A, Marks V. Serum immunoreactive trypsin concentrations in infectious and non-infectious 
illnesses and in juvenile diabetes. J Clin Pathol 1979;32: 897-901.

- Lake-Bakaar G, Smith-Laing G, Summerfield JA. Origin of serum trypsin; evidence for intestinal reabsorption. Gut 1978;19:A445 (abstract).

${ }^{2}$ Hanssen E. The formation of pancreatic juice proteins studied with labelled aminoacids. Acta Physiol Scand 1959;46 Suppl 161, 1-99.

${ }^{8}$ Henderson JR. Why are the islets of Langerhans? Lancet $1969 ; 2: 469-70$

- Frier BM, Faber OK, Binder C, Elliott HL. The effect of residual insulin secretion on exocrine pancreatic function in juvenile-onset diabetes mellitus. Diabetologia 1978;14:301-4.

10 Zajtchuk R, Amato JJ, Poloyan E, Baker RJ. Inhibition of pancreatic exocrine secretion by glucagon. Surg Forum $1967 ; 18: 410-1$.

${ }^{11}$ Lankisch PG, Arnold R, Creutzfeldt W. Werkung von Somatostatin auf die betazol-stilulierte Magensekretion und die carbachol-stimulierte Pancrease-secretion und Gallen-blasenkontraktion des Menschen. Dtsch Med Wochenschr 1975;100:1797-1800.

12 Dollinger HC, Raptis S, Pfeiffer EH. Effects of somatostatin in exocrine and endocrine pancreatic function stimulated by intestinal hormones in man. Horm Metab Res 1976;8:74-8.

${ }^{13}$ Greenberg GR, Adrian TE, Baron JH, McCloy RF, Chadwich VS, Bloom SR. Inhibition of pancreas and gall bladder by pancreatic polypeptide. Lancet 1978;2: 1280-2.

14 Gepts W, de Meys I, Marichal-Pipeleers M. Hyperplasia of 'pancreatic polypeptide' cells in the pancreas of juvenile diabetics. Diabetologia 1977;13:27.

Requests for reprints to: Dr DR Gamble, Public Health Laboratory, West Park Hospital, Epsom, Surrey KT19 8PB, UK. 